\title{
Neurofibromatosis and leprosy ${ }^{1}$
}

\author{
THOMAS R. SWIFT
}

\begin{abstract}
From the Rehabilitation Branch, USPHS Hospital, Carville, Louisiana, and Louisiana State University School of Medicine, U.S.A.
\end{abstract}

SUMMARY Two patients with neurofibromatosis and leprosy are reported. Both had active lepromatous leprosy and generalized neurofibromata. The bacilli appear in huge numbers within the cytoplasm of the cells making up the neurofibromata, which become distended and resemble lepra cells. Since these cells are believed to derive from Schwann cells, the findings in these patients support the idea that leprosy affects nerves initially by proliferating in Schwann cells and producing changes within them.

The coexistence of leprosy and neurofibromatosis in the same patient is interesting in that both appear to be disorders of the Schwann cell. Recent electron microscopic studies (Chino and Tsuruhara, 1968; Fisher and Vuzevski, 1968) have demonstrated that most cells in neurofibromata and acoustic tumours derive from Schwann cells. The evidence relates to the presence of a basement membrane $500 \AA$ thick, unmyelinated axons invaginated into the cells, and a tendency for these cells to wrap themselves up in their own processes. In leprosy the traditional view, held by Dehio (1897) and elaborated by Khanolkar (1951) and others (Nishiura, Harada, and Imaeda, 1957; Imaeda and Convit, 1963) that $M$. leprae were intra-axonal and spread along nerves by that route, has recently been challenged. The electron microscope has shown that the Schwann cell, and not the axon, is predominantly (or possibly even solely) invaded by Mycobacterium leprae (Job, 1970; Locke and Umlas, 1970). In these electron micrographs bacilli are seen clearly within Schwann cell cytoplasm while axonal cytoplasm is free of bacilli. The idea of selective involvement of the Schwann cell by $M$. leprae receives added support from the findings of Job and Desikan (1968) in which stains for myelin show significantly greater demyelinization than axonal destruction in nerves from lepromatous leprosy. Recently, Dayan and Sandbank (1970) have shown demyelinization due to Schwann cell damage in teased nerve preparations from a case of lepromatous leprosy. Determining the localization of $M$. leprae in patients with both neurofibromatosis and leprosy, and noting the reaction of the tumour cells

${ }^{1}$ This work was supported by Social and Rehabilitation Service Grant No. RC 75 MPO. to the presence of $M$. leprae would be additional evidence for the importance of the Schwann cell in leprosy and also be helpful in understanding the pathophysiology of nerve involvement in this disease. Johansen and McCreary reported a patient with von Recklinghausen's neurofibromatosis and lepromatous leprosy in 1936. They describe the neoplastic cells as being parasitized by $M$. leprae; however, they show no pathological material in their report. The purpose of the present report is to describe the pathological changes in their case and to describe a subsequent patient with both diseases admitted to the National Leprosarium at Carville.

CASE 1

(No. 1015.) The patient was a 42 year old MexicanAmerican male. For 15 years he had noted numerous small nodular tumours all over his body. For two years he had had an eruption on his face and body and severe nasal stuffiness. He also had a five to six year history of recurrent right-sided pleuritic chest pain, and a two year history of weakness, anorexia, and $13.6 \mathrm{~kg}$ (30 lb.) weight loss.

PHYSICAL EXAMINATION There was nodular thickening on the face and forehead and the earlobes were enlarged (Fig. 1A). Many of the small nodules on the forehead were firm. There were numerous copper-coloured nodules varying from pinhead to several centimetres in size on the trunk and extremities (Fig. 1B). These were quite soft and some were pedunculated. A few of the nodules appeared to be firm and thickened like the nodules of leprosy. There were also a few scattered brown patches on the body and thighs. These were ovoid with smooth margins and without central depigmentation. He had marked anaesthesia in the hands and feet. The thenar muscles were atrophied. Both ulnar, left great 

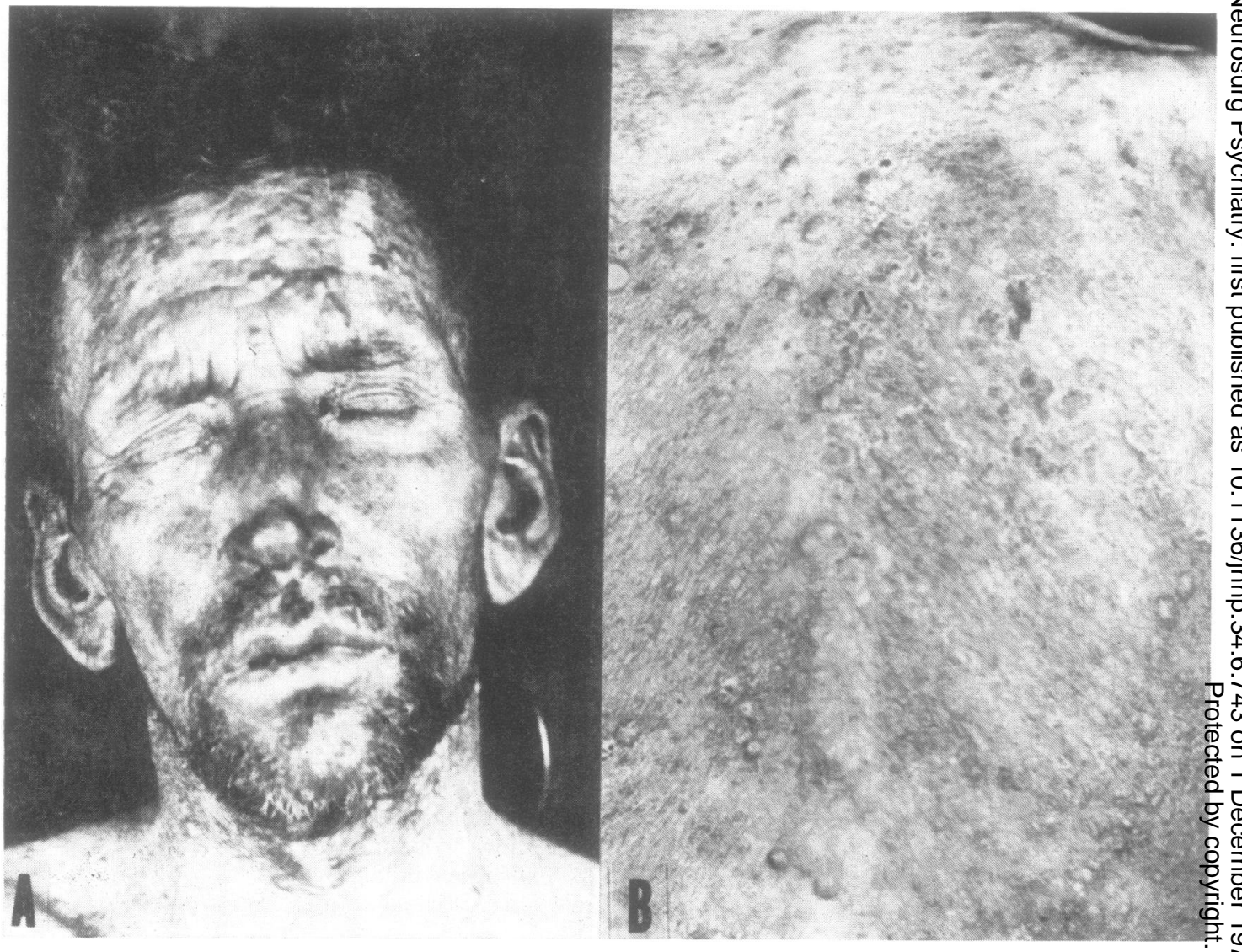

FIG. 1. Patient 1. A. Numerous discrete nodules are seen. Supraorbital tissues and earlobes are thickened. Outer onehalf of eyebrows are scanty. B. Nodules are seen on the back. Some fissuring also is present.

auricular, and both peroneal nerves were palpable. The outer one-half of the eyebrows were scanty (Fig. 1). There was loss of sweating in the distal portions of the extremities. There was auscultatory evidence of consolidation of the right lung and left apex. Radiographs of the chest were compatible with far advanced pulmonary tuberculosis. The Kolmer test was positive.

PATHOLOGICAL EXAMINATION Skin biopsy revealed numerous $M$. leprae. One of the small tumours was biopsied. The epidermis was thin with flattened rete. A clear zone was seen in the dermis, beneath which was the tumour (Fig. 2A). It consisted of spindle-shaped cells with elongated nuclei which formed whorls about nerve fibres, other tumour cells, or blood vessels (Fig. 2B). In some areas the cells were elongated and formed palisades (Fig. 2C, D). In others, they had paler-staining nuclei, more rounded appearance, and more lacy cytoplasm (Fig. 2E, F). The latter apparently corresponded to the cells containing bacilli seen on the acid-fast stain.
Numerous mast cells were scattered throughout, and $\stackrel{\circ}{\mathscr{D}}$ there was marked capillary proliferation. The acid-fast $\overrightarrow{\vec{P}}$ stained sections have been lost but the following were reported by Johansen and McCreary (1936): innumerable acid-fast bacilli throughout a large portion of the tumour, in the neoplastic cells. Many of these formed globi. Acidfast bacilli also were seen in the normal corium.

\section{CASE 2}

(No. 2937.) The patient was a 59 year old white female American. She had noted numerous nodules all over her body since the age of 22, and had been operated upon for severe gastrointestinal bleeding from neurofibromata of the jejunum which were removed. She was diagnosed as having leprosy on the basis of a liver biopsy done at the time of her laparotomy. She had been aware of loss of sensation in her feet for at least seven years and had a $\sigma$ history of recurrent painless injuries to her legs, feet, and $N$ hands. She also complained of nasal stuffiness and had 


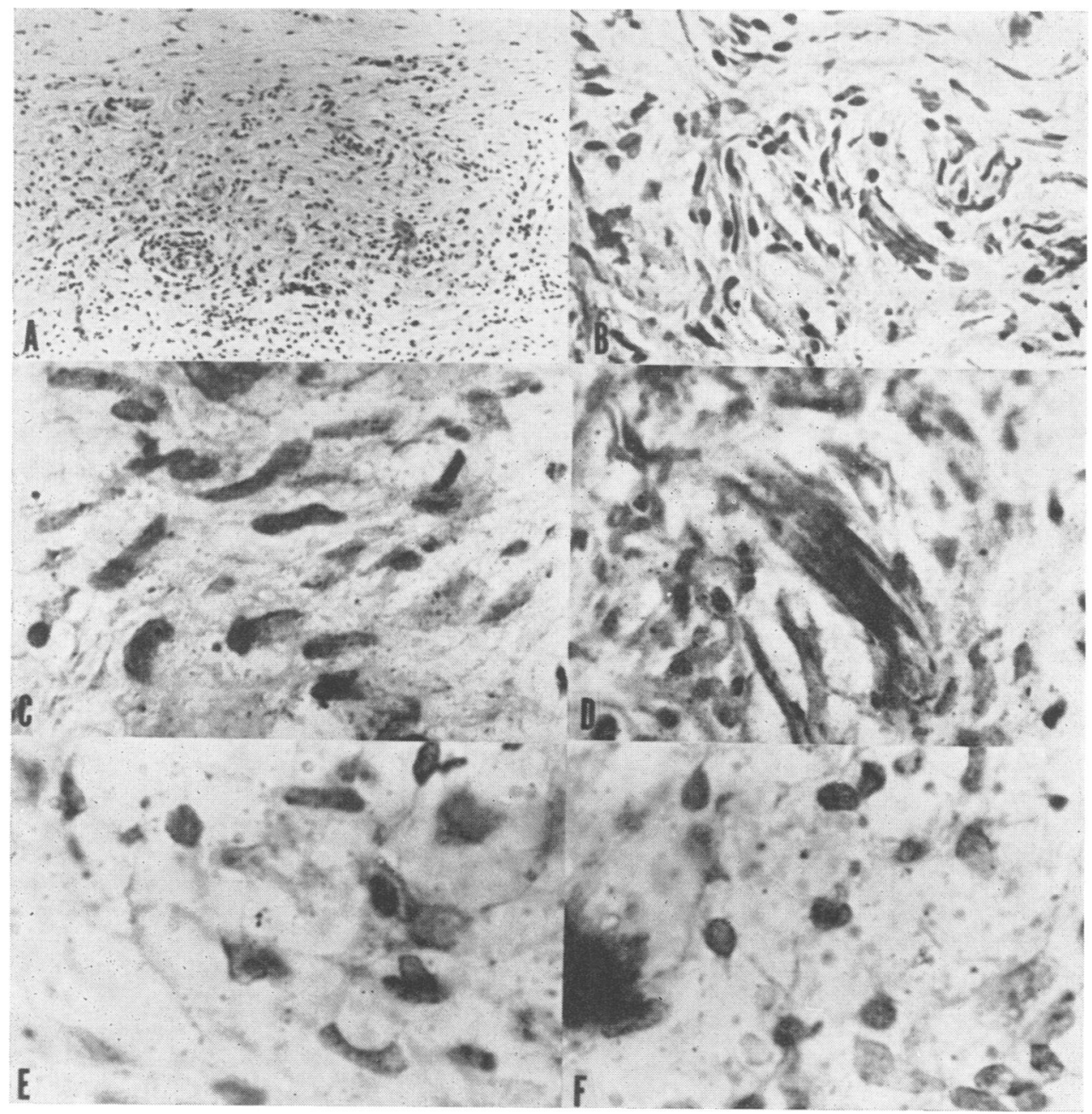

FIG. 2. Patient 1. A. Clear zone is seen in tissue at top of Figure. Tumour shows fusiform and round cells, with whorling about nerves and blood vessels. $H$ and $E, \times 67$. B. Area of fusiform cells showing streaming and whorling. $H$ and $E, \times 300 . C$. Close-up of fusiform cells. $H$ and $E, \times 667 . D$. Palisading of cells. $H$ and $E, \times 300$. E. and F. Round cells in tumour with clear cytoplasm and pale nuclei. $H$ and $E, \times 667$.

become a mouth breather. Her eyes felt 'gritty' and were dry.

She had been diagnosed as hypothyroid many years before on the basis of a low protein-bound iodine in the serum and low $I_{131}$ uptake and had been on replacement medication. She had the additional complaint of whitening of her fingers upon exposure to cold.

PHYSICAL EXAMINATION The patient was a thin, elderly white female. The skin revealed numerous nodules (several millimetres to several centimetres in size) all over her face and body, many of which followed the courses of nerves (Fig. 3A, B). There were several café au lait spots (Fig. 3C). Mental status and cranial nerves were normal except for minimal weakness of eye closure bilaterally. There was weakness of dorsiflexion of the left foot and of extension and flexion of the toes bilaterally, and mild left ulnar weakness. Reflexes were active and equal but with delayed relaxation typical of hypothyroidism. Sensory examination revealed normal position and vibration sense throughout. There was an extensive loss to pricking pain, temperature, and light 


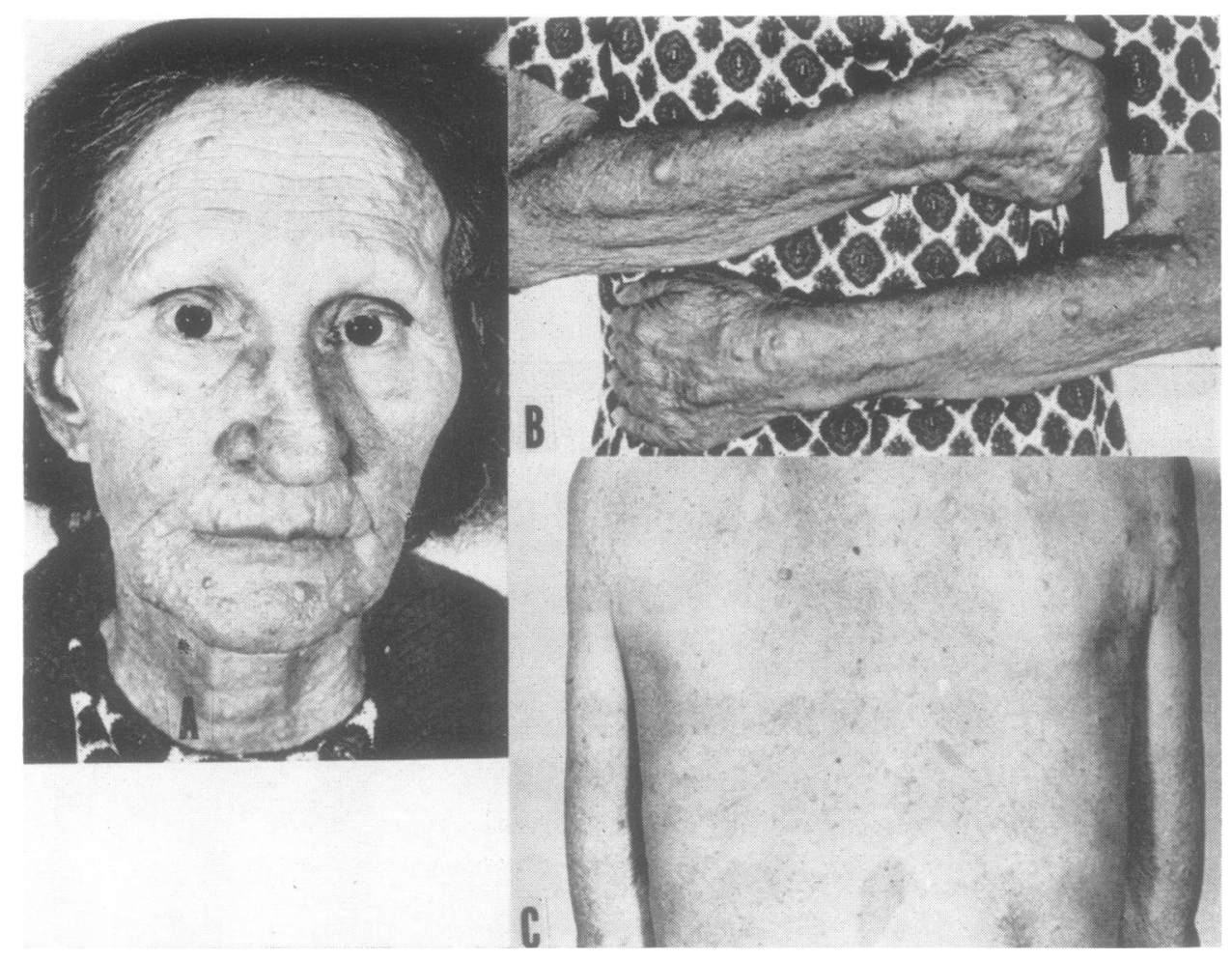

FIG. 3. Patient 2. A. Loss of eyebrows is apparent. Many nodules are present, especially about the chin and neck. B. Many nodules are present on the arms varying from several millimetres to over $1 \mathrm{~cm}$. C. Several large neurofibromata and café au lait spots are seen.

touch over the extremities, face, and trunk involving cool areas of the ears, nose, dorsa of hands, legs, and feet with sparing of warmer surfaces such as scalp, axillae, anticubital fossae, groin, and gluteal cleft. Palpation of nerves revealed nodular enlargements which were neurofibromata along many nerves, particularly the intercostals and the right superficial radial cutaneous nerve. There were also fusiform enlargements and hardening of the left ulnar nerve above the ulnar groove at the elbow, both superficial radial cutaneous nerves, and both peroneal nerves, thought typical of lepromatous leprosy.

Motor nerve conduction velocities revealed slight slowing of the right median nerve between elbow and wrist $(47.5 \mathrm{~m} / \mathrm{sec})$ and right ulnar nerve mid arm to elbow $(45.1 \mathrm{~m} / \mathrm{sec})$. (Minimum normal values for her age in our laboratory are $50.5 \mathrm{~m} / \mathrm{sec}$ and $52.2 \mathrm{~m} / \mathrm{sec}$, respectively).

PATHOLOGICAL EXAMINATION Skin biopsy revealed more than half of the dermis infiltrated by typical lepra cells. Between the lepra cells and the flattened epidermis was a clear zone. Acid-fast stain of the skin biopsy revealed numerous bacilli. Scrapings from multiple skin sites wer⿳亠口冋้ all highly positive with innumerable organisms seen.

Biopsy of a neurofibroma on the right back was studief with haemotoxylin and eosin and acid-fast stains. Thi skin was thin with no rete. Below the epidermis was a clear zone under which was the tumour (Fig. 4A). The tumour contained many nerve fibres (Fig. 4B) and thie tumour cells appeared to form whorls about the nerve fibres and the numerous capillaries (Fig. 4C). Manक appeared to wrap around themselves (Fig. 4D). The celig differed in size and shape cepənding on their degree of. parasitization with $M$. leprae. Some were spindle-shapeg with elongated nuclei (Fig. 4E). On acid-fast staining these were seen in areas where there were few or $n 8$ bacilli (Fig. 5A). Others were plump with round vesiculap nuclei and clear cytoplasm (Fig. 5B). These cells appeare almost to burst with huge numbers of bacilli (Fig. 5C, E) and even formed globi. Transitional forms could be found between these two types of cell. The tumour cells often wrapped themselves about other tumour celg containing bacilli (Fig. 5F). 


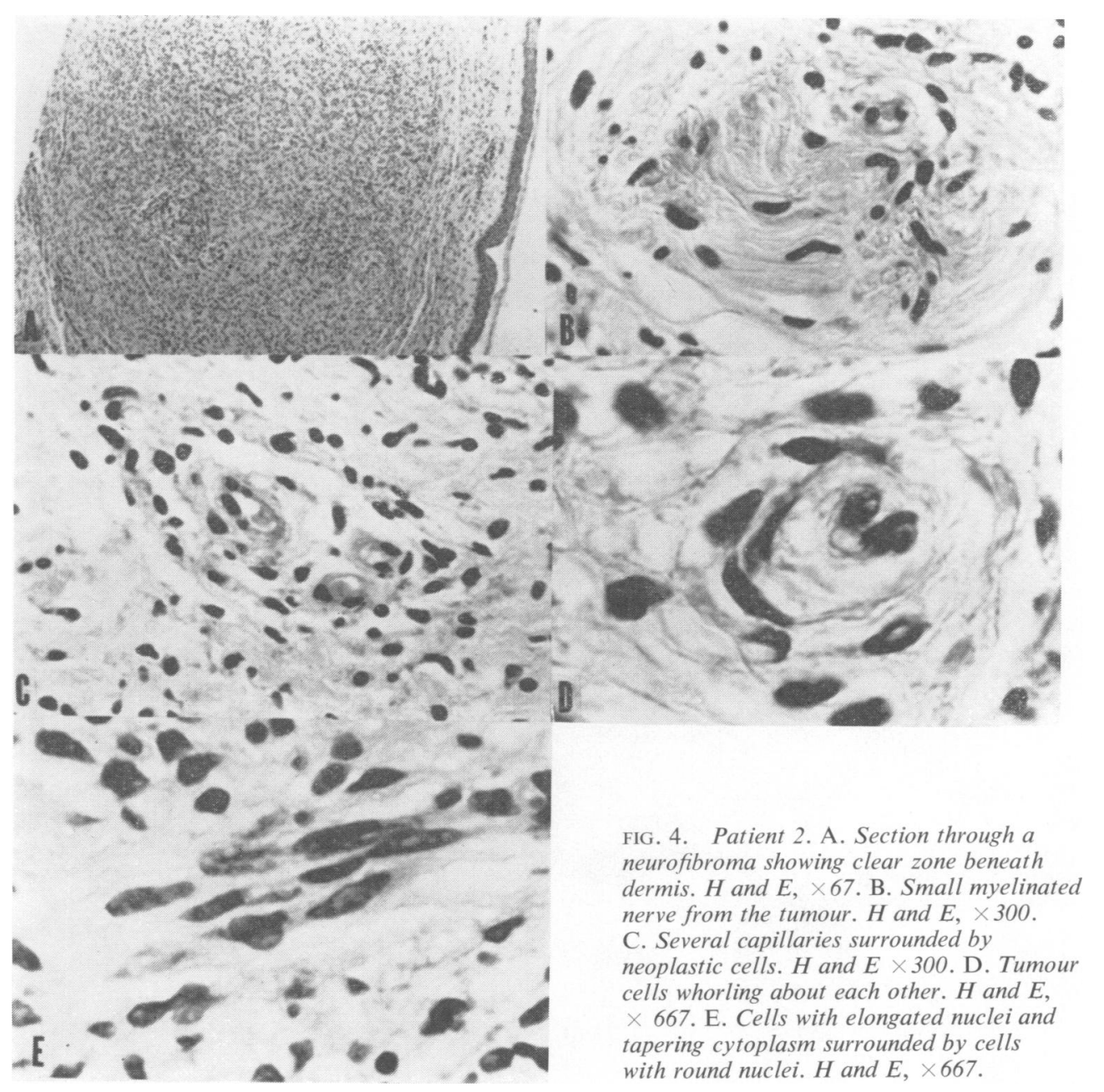

\section{DISCUSSION}

Both patients had lepromatous leprosy, active at the time of biopsy, and both patients had skin lesions typical of von Recklinghausen's disease with numerous fleshy tumours and café au lait spots. On microscopic section, tumours from both patients were typical of neurofibromata. The major findings of histological interest relate to the preferential localization of the bacilli within tumour cells and the transformations of these cells in a manner typical of Schwann cells in lepromatous leprosy. Many tumour cells were packed with bacilli to a much greater degree than surrounding normal tissue cells. Some of these cells formed globi. Schwann cells from this tumour and also from excised schwannomas as shown experimentally apparently have no difficulty phagocytosing $M$. leprae but are unable to destroy them. Lumsden (1964) has shown that tissue cultures from human schwannomas demonstrate active phagocytosis for $M$. leprae which is more intense than that shown by a variety of other kinds of normal tissue cells. However, once ingested the bacilli are not destroyed but remain in large masses in the distended cytoplasm surrounded by clear zones.

The cellular changes in response to the bacterial infection in these patients' tumour cells were quite characteristic of Schwann cell changes in leprosy. The tumour cells, most of which initially were 


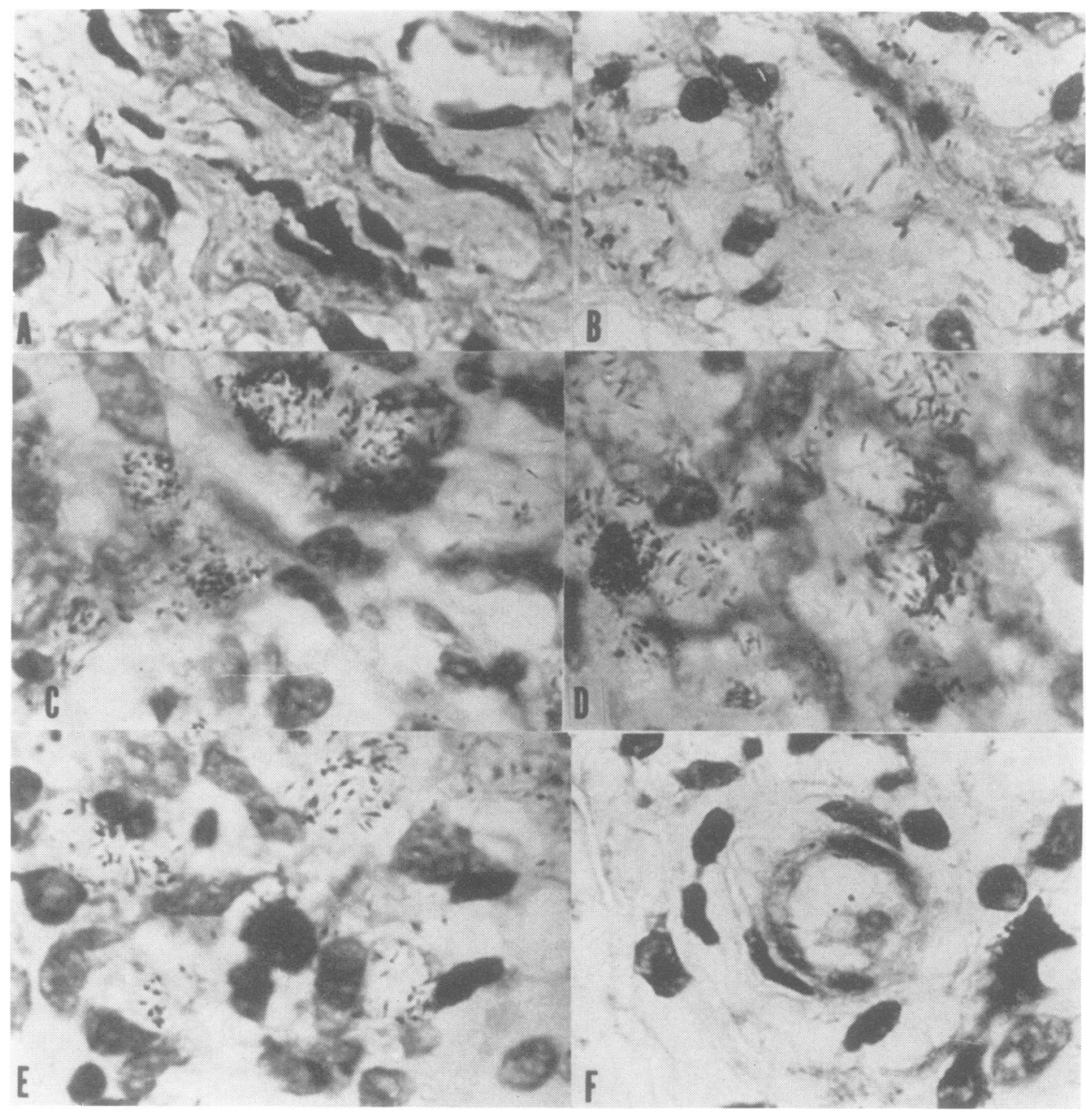

FIG. 5. Patient 2. A. Spindle cells showing few bacilli. Acid-fast stain, $\times 667$. B. Round cells with vesicular nuclei and clear cytoplasm. Many bacilli are seen within the cells. Acid-fast stain, $\times 667$. C., D., and E. Tumour cells with huge numbers of bacilli. Several form globi. Acid-fast stain, $\times 667$. F. Tumour cells whorling about a cell containing a few disintegrating bacilli. Acid-fast stain, $\times 667$.

spindle-shaped with elongated nuclei became round with plump nuclei and lacy cytoplasm, associated with increasing numbers of intracellular $M$. leprae. Job (1970) has shown this same change with the electron microscope in Schwann cells from nerve in lepromatous leprosy. In cells with one or few bacilli the organisms appear to lie in the cytoplasm often with an electron-transparent zone surrounding them. This clear zone enlarges as the number of bacilli parasitizing the cell increases until a cell with dis- tended cell membrane and clear cytoplasm packed $\frac{0}{3}$ with bacilli is produced. Such heavily laden ballooned cells as were seen in these two cases are indistinguishable from lepra cells. Lepra cells are those which produce the intense infiltration of the $\frac{9}{3}$ skin with extremely high bacillary counts in the $\frac{?}{0}$ disease.

The origin of lepra cells in lepromatous leprosy $N$ is unclear. Some workers feel that these cells are converted macrophages (Hanks, 1954), however others 
believe they represent the proliferation of altered Schwann cells (Lumsden, 1964). Schwann cells undergo such changes in tissue culture (Lumsden, 1964). In lepromatous leprosy the nerves may not be infiltrated by cells originally outside the nerve, but rather by proliferation of Schwann cells within the nerve in response to the presence of $M$. leprae.

This predilection of the mycobacteria for Schwann cells in these two cases explains some features of the neurological picture. Many of the cells of the neurofibromata hold great numbers of bacilli and yet still appear viable. In patients, nerves may be densely infiltrated with cells holding great numbers of bacilli and yet show little functional disturbance early in the disease. In case 2, although nerves were palpably enlarged due to lepromatous leprosy, motor nerve conduction velocities were normal or near normal. This is not unusual and has been reported (Hackett, Shipley, and Livengood, 1968).

I would like to express my thanks to Dr. Lewis Cummings for permission to study his patient (case 2).

\section{REFERENCES}

Chino, F., and Tsuruhara, T. (1968). Electron microscopic study of von Recklinghausen's disease. Jap. J. Med. Sci. Biol., 21, 249-257.
Dayan, A. D., and Sandbank, U. (1970). Pathology of the peripheral nerves in leprosy: report of a case. J. Neurol. Neurosurg. Psychiat., 33, 586-591.

Dehio, K. (1897). (Cited by Lie, H. P.) (1905). Lepra im Rückenmark und der peripheren Nerven. Arch. Derm. Syph. (Berl.), 73, 171-244.

Fisher, E. R., and Vuzevski, V. D. (1968). Cytogenesis of Schwannoma (neurilemoma), neurofibroma, dermatofibroma, and dermatofibrosarcoma as revealed by electron microscopy. Amer. J. Clin. Path., 49, 141-154.

Hackett, E. R., Shipley, D. E., and Livengood, R. (1968). Motor nerve conduction velocity studies of the ulnar nerve in patients with leprosy. Int. J. Leprosy, 36, 282-287.

Hanks, J. H. (1954). The implications of Suter's review of intracellular parasitism with respect to the problem of leprosy. Int. J. Leprosy, 22, 12-15.

Imaeda, T., and Convit, J. (1963). Electron microscope study of cutaneous nerves in leprosy. Int. J. Leprosy, 31, 188-210.

Job, C. K., and Desikan, K. V. (1968). Pathologic changes and their distribution in peripheral nerves in lepromatous leprosy. Int. J. Leprosy, 36, 257-270.

Job, C. K. (1970). Mycobacterium leprae in nerve lesions in lepromatous leprosy. An electron microscopic study. Arch. Path., 89, 195-207.

Johansen, F. A., and McCreary, F. D. (1936). Leprosy and von Recklinghausen's disease. Int. J. Leprosy, 4, 485-487.

Khanolkar, V. R. (1951). Studies in the Histology of Early Lesions in Leprosy. Indian Council of Medical Research. Special Report Series, No. 19.

Locke, S., and Umlas, J. (1970). Unusual rash and sensorimotor neuropathy. New Engl. J. Med., 282, 1144-1152.

Lumsden, C. E. (1964). Leprosy and the Schwann cell in vivo and in vitro. In Leprosy in Theory and Practice, edited by R. G. Cochrane and T. F. Davey, 2 nd edn. Wright: Bristol.

Nishiura, M., Harada, N., and Imaeda, T. (1957). Electron microscopy of ultra-thin sections of lepromatous peripheral nerves. Int. J. Leprosy, 25, 323-328. 